\title{
Blood Smear and Diagnosis of Anaemia in Children: Experience of the Hematology Laboratory of the Avicenna Hospital in Rabat with Review of the Literature
}

\author{
Sophia Kahouli ${ }^{1, ~ *}$, Azelarab Masrar ${ }^{2}$, Leila Hessissen ${ }^{3}$, Maria Kababri ${ }^{3}$, Amina Kili ${ }^{3}$, \\ Mohamed El Khorassani ${ }^{3}$ \\ ${ }^{1}$ Laboratory of Research and Medical Analysis of the Fraternal of the Royal Gendarmerie, Faculty of Medicine and Pharmacy, Mohammed V \\ University, Rabat, Morocco \\ ${ }^{2}$ Central Hematology Laboratory, Ibn Sina Hospital, Faculty of Medicine and Pharmacy, Mohammed V University, Rabat, Morocco \\ ${ }^{3}$ Pediatric Hematology and Oncology Service of Children's Hospital, Faculty of Medicine and Pharmacy, Mohammed V University, Rabat, \\ Morocco
}

\section{Email address: \\ skahouli@Iram-fgr.ma (S. Kahouli) \\ ${ }^{*}$ Corresponding author}

\section{To cite this article:}

Sophia Kahouli, Azelarab Masrar, Leila Hessissen, Maria Kababri, Amina Kili, Mohamed El Khorassani. Blood Smear and Diagnosis of Anaemia in Children: Experience of the Hematology Laboratory of the Avicenna Hospital in Rabat with Review of the Literature. European Journal of Clinical and Biomedical Sciences. Vol. 6, No. 3, 2020, pp. 43-48. doi: 10.11648/j.ejcbs.20200603.13

Received: June 27, 2020; Accepted: August 4, 2020; Published: August 13, 2020

\begin{abstract}
The discovery of anemia in children requires a rigorous approach to determine its etiology. This approach is essentially based on the biological analysis of the haemogram and the blood smear. The aim of our study is to demonstrate the vital interest of the blood smear in the diagnosis of anemia in children and to sensitize clinicians and biologists to the value of an adequate interpretation of the blood count. It is indeed a prospective study conducted at the Department of Pediatrics in collaboration with the Central Hematology Laboratory of the Ibn Sina University Hospital in Rabat, from May to July 2019. This study involved 100 cases of anemic infants and children who underwent a blood count and a blood smear. Childhood anaemia is predominantly male (56\%), the most represented age group is between 1 month and 5 years $(34 \%)$, according to the $\mathrm{Hb}$ rate, moderate anaemia is the most frequent (51\%), the type of anaemia most found is $10 \%$, the most common hue abnormality is the presence of annulocytes (37\%), the anomalies of the are diverse but the most dominant are the presence of schizocytes $(81 \%)$ followed by elliptocytes $(68 \%)$, only basophilic wells are present as intraerythrocytic inclusions $(1 \%)$. Our results are consistent with those in the literature and illustrate the vital interest of the hematologist in the diagnosis of the child.
\end{abstract}

Keywords: Anaemia, Blood Smear, Child, Erythrocyte Abnormalities, Etiological Diagnosis, Haemogram

\section{Introduction}

Anaemia is a widespread public health problem, with major consequences for individual health as well as economic and social development. It affects more than 2 billion people worldwide, according to WHO estimates. The disease is the most common abnormality of the blood count [1]. The discovery of anaemia in children raises the question of its etiology. While many causes of anaemia are easily identifiable, there are a number of situations in which no specific diagnosis is obvious. A rigorous and hierarchical approach must be used to understand its mechanism and consider its etiology. While automated machines provide the initial arguments for this investigation, the study of the morphology of red blood cells on the blood smear provides essential elements in the process of diagnosing anaemia. Indeed, the abnormalities on blood smears are multiple, they mainly concern the size, colour and shape of red blood cells. Abnormalities in size and colour mainly indicate a production disorder due to abnormalities in haemoglobin or nucleic acid synthesis.

The interpretation of shape abnormalities is tricky because some numbers are not specific to a given constitutional 
pathology and are also found in acquired conditions. Thus, an enlightened reading of red blood cell morphology is rich in information, but it is often neglected and cannot be useful without complete clinical information [2].

The objective of our study is to demonstrate the primary interest of the blood smear in the etiological diagnosis of anaemia in children, and to describe the different abnormalities by specifying the pathologies to which they are related.

\section{Materials and Methods}

This is a prospective, descriptive and analytical study carried out within the haematology-oncology unit of the paediatric department of the Rabat children's hospital, in collaboration with the central haematology laboratory of the Ibn Sina University Hospital in Rabat, over a period of three months (May to July 2019). The inclusion criteria concerned all children suspected of anaemia. Patients underwent a blood count and a blood smear. Data for this study were collected using the laboratory requisition form completed for each patient by the prescribing physician. For each of the children included in our study, a minimum of $2 \mathrm{ml}$ of venous blood was placed in purple-capped tubes containing EDTA (ethylene diamine tetra acetic acid). The sample may also include capillary blood (finger pulp, heel in infants) in calibrated microtubes [3]. The blood count is performed on the DXH800. The blood smear is taken on the Sysmex SP$1000 \mathrm{i}$ analyzer. The staining of the blood smear is done on the RAL Stainer.

\section{Results}

Our work involved 100 patients, 56 of the cases were male subjects and 44 of the cases were female subjects. The age of the patients ranged from 1 month to 18 years, with a mean of 7 years and 5 months, and a standard deviation of 5 years. Figure 1.

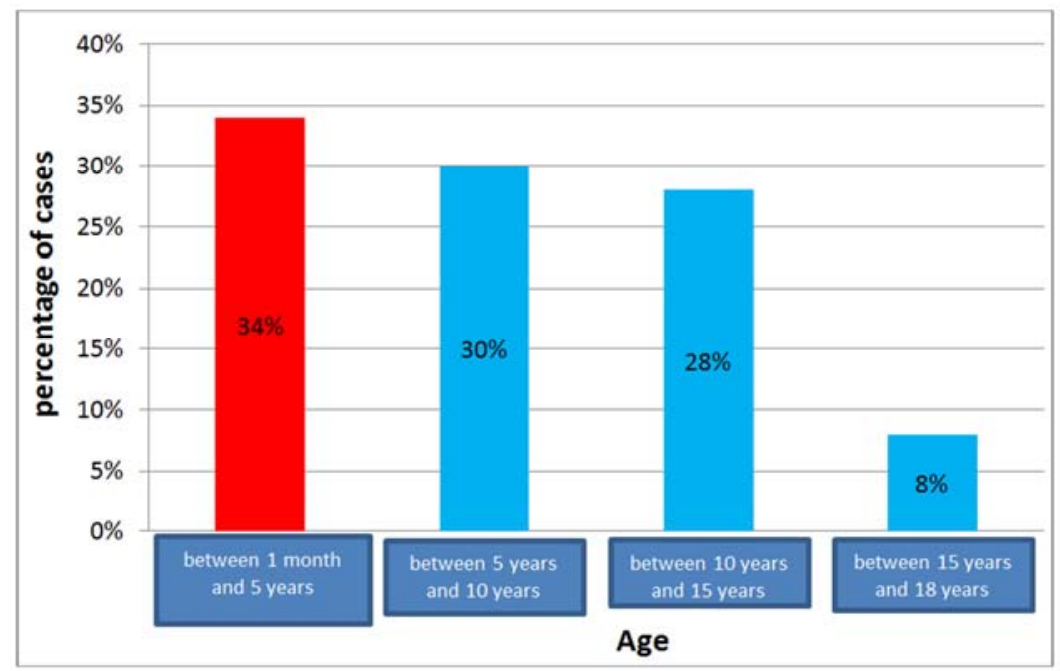

Figure 1. Age distribution of patients.

Haemoglobin values ranged from 3.6 to $13.2 \mathrm{~g} / \mathrm{dl}$ with a mean of $8.61 \mathrm{~g} / \mathrm{dl}$ and a standard deviation of $2.04 \mathrm{~g} / \mathrm{dl}$. Moderate anemia was the most pronounced with a frequency of $51 \%$ for both sexes Figure 2.

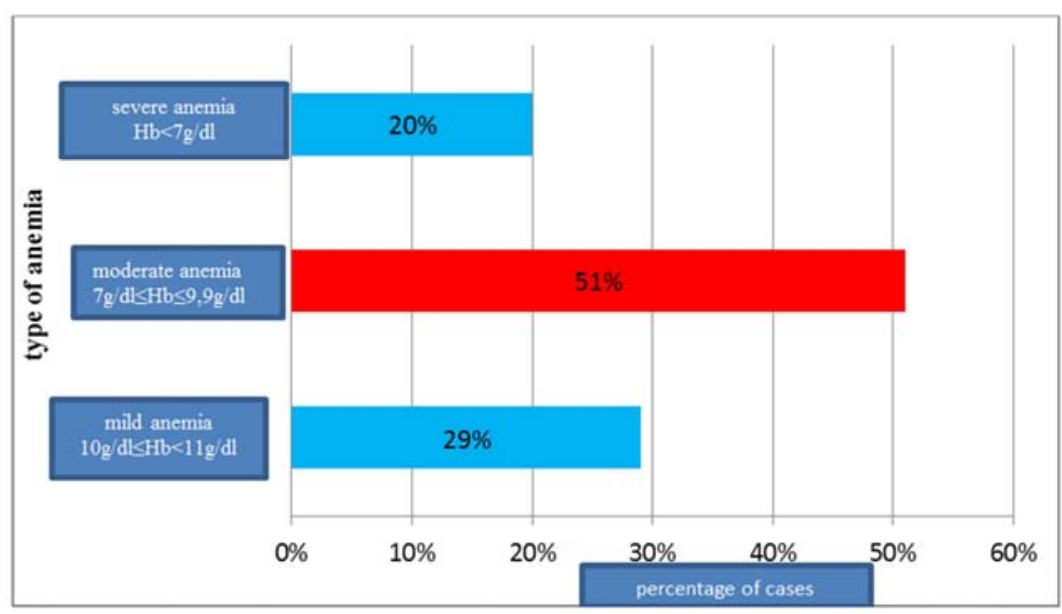

Figure 2. Distribution of cases by Hb level. 
Mean corpuscular volume (MCV) values ranged from 70.2 to $102.6 \mathrm{fl}$, with a mean of $83.66 \mathrm{fl}$ and a standard deviation of $7.79 \mathrm{fl}$. The MCV study showed a slight predominance of normocytic anemia in $54 \%$ of patients.

The values of the mean corpuscular hemoglobin concentration (MCHC) varied between 27.4 and $37.6 \%$, with a mean of $33.44 \%$ and a standard deviation of $1.73 \%$. According to the levels of MCHC found normocytic normochromic anemia is the most frequent with a percentage of $42 \%$ (Table 1$)$.

Table 1. General classification according to MCV and MCHC.

\begin{tabular}{lll}
\hline Type of anaemia & Number of cases & Frequency \\
\hline Hypochromic microcytic anaemia & 7 cases & $7 \%$ \\
Normochromic microcytic anaemia & 31 cases & $31 \%$ \\
Hypochromic normocytic anaemia & 10 cases & $10 \%$ \\
Normochromic normocytic anaemia & 42 cases & $42 \%$ \\
Hypochromic macrocytic anaemia & 2 cases & $2 \%$ \\
Normochrome macrocytic anaemia & 3 cases & $3 \%$ \\
\hline
\end{tabular}

The mean corpuscular hemoglobin concentration (MCHC) levels are 20.4 and $35.3 \mathrm{pg}$ with a mean of $28.07 \mathrm{pg}$ and a standard deviation of $2.97 \mathrm{pg}$. The red cell distribution width (RDW) values range from 11.3 to $31.7 \%$ with a mean of $17.96 \%$ and a standard deviation of $4.30 \%$. Thus $82 \%$ of patients had anisocytosis.

Blood smear analysis found the following abnormalities, which may be isolated, or most often associated in the same patient:

1. Size abnormalities are represented by macrocytosis in $10 \%$ of patients, and microcytosis in $2 \%$ of patients.

2. Colour abnormalities such as annulocytes were observed in $37 \%$ of cases, and polychromatophilia in $30 \%$ of patients.

3. The shape anomalies with the most dominant aspect is that of schizocytes found in $81 \%$ of patients, the elliptocytes found in $68 \%$ of patients and the dacryocytes found in $64 \%$ of patients.

Other shape abnormalities encountered were as follows: stomatocytes in $44 \%$ of cases; acanthocytes in $39 \%$ of patients; target red blood cells in $28 \%$ of patients; echinocytes in $20 \%$ of patients; sickle cells (sickles) in $11 \%$ of patients; mushroom red blood cells in $4 \%$ of patients; spherocytes in $2 \%$ of patients; phantom red blood cells only in $1 \%$ of patients; intraerythrocytic inclusions were observed only in $1 \%$ of patients in the form of basophilic punctuations.

\section{Discussion}

Anaemia is a frequent reason for consulting a paediatrician. It is biologically defined and is age-dependent in children. It is defined by a decrease in the haemoglobin level below two standard deviations from the average for the child's age. (Table 2) [3].
Table 2. Haemoglobin norms according to age [3].

\begin{tabular}{lll}
\hline \multirow{2}{*}{ Age } & \multicolumn{2}{l}{ Haemoglobin $(\mathbf{g} / \mathbf{d l})$} \\
\cline { 2 - 3 } & Mean & 2 DS below average \\
\hline 1 to 3 days & 18.5 & 14.5 \\
2 weeks & 16.6 & 13.4 \\
1 month & 13.9 & 10.7 \\
2 months & 11.2 & 9.4 \\
6 months & 12.6 & 11.1 \\
6 months to 2 years & 12.0 & 10.5 \\
2-6 years & 12.5 & 11.5 \\
6 to 12 years old & 13.5 & 11.5 \\
12 to 18 years old (male) & 14.5 & 13.0 \\
12 to 18 years old (female) & 14.0 & 12.0 \\
\hline
\end{tabular}

In the normal state, all red blood cells (RBCs) have approximately the same shape, diameter and colour under the microscope and any change in these criteria reflects a pathological phenomenon. The structure of red blood cells is schematically broken down into three components: membrane, enzymes, and hemoglobin [2, 4]. The diagnosis of childhood anemia is clinico-biological.

It is based on an accurate questioning with a complete clinical examination, and on the haemogram following the interpretative study of haemoglobin levels and red blood cell constants (MCV, MCHC, MCH...).

It was classical to interpret the hemoglobin figures as a function of the erythrocyte constants far from the morphological data. The study of erythrocyte morphology on a blood smear often guides the diagnosis of anemia in children.

Abnormalities in hemoglobin, membrane or red blood cell enzyme content result in suggestive morphological changes. The detection of these morphological abnormalities will allow the implementation of complementary examinations that will lead to a precise diagnosis. These morphological abnormalities are classified into four categories, namely abnormalities in size, colour, shape and the presence or absence of various inclusions [5-7].

Size anomalies

Anisocytosis is caused by changes in red blood cell production and by the transfusion of red blood cells. It is defined at the microscopic level by the existence of red blood cells of all sizes. This abnormality is not very helpful in determining a precise etiology. Microcytosis is defined by the presence of red blood cells of decreased size with decreased MCV but normal thickness. This differentiates these cells from spherocytes. Macrocytosis, the latter is defined by the presence of red blood cells of increased size with elevated $\mathrm{MCV}$.

It is usually related to an abnormality in DNA synthesis (deficiency in vitamin B12, folic acid, deficiency in uridine monophosphate (UMP) synthetase) [8-10] (Table 3). 
Table 3. Most frequent pathologies depending on the type of anaemia [8, 10].

\begin{tabular}{lll}
\hline Microcytic anaemia & Normocytic anaemia & Macrocytic anaemia \\
& Inflammatory anaemia & \\
Iron deficiency & Acute bleeding & Fanconi anaemia \\
Thalassemia & Transient erythroblastopenia of childhood & Medullar aplasia \\
Inflammatory anaemia & Blackfan-Diamond anaemia & Trisomy 21 \\
Lead poisoning & Autoimmune hemolytic anaemia & Hypothyroidism \\
& Sickle cell anaemia & Vitamin B12 or B9 deficiency \\
& Hereditary spherocytosis & \\
\hline
\end{tabular}

The analyser gives a better estimate of macrocytosis and microcytosis than a blood smear. However, the diagnosis of microcytosis in Minkowski-Chauffard disease is oriented to the blood smear.

\section{Colour anomalies}

Several abnormalities are described in relation to variations in the intensity of staining of the cytoplasm of red blood cells. In our study, the most common staining defect was the presence of annulocytes. The term leptocyte or annulocyte refers to red blood cells of which only the periphery appears stained. This is due to a decrease in haemoglobin or, on the contrary, an increase in the surface area of the membrane (jaundice by retention). Annulocytes are usually found in cases of iron deficiency.

Polychromatophilia, on the other hand, corresponds to the presence of slightly grey-blue red blood cells of high size. These are young red blood cells containing RNA residues. They reflect an intense medullary regenerationThey reflect intense bone marrow regeneration and are found in all constitutional anemias with high reticulocytosis. Hypochromia corresponds to the presence of lighter than normal red blood cells, related to a decrease in haemoglobin concentration.

It is linked either to a defect in heme synthesis (iron deficiency, congenital sideroblastic anaemia), or to a defect in globin chain synthesis (thalassaemia) [8].

Anomalies of form

Schizocytes are fragmented red blood cells that can have different shapes (triangle, crescent, helmet). When their threshold constitutes 5 to $20 \%$ of the red blood cells, i.e. approximately 5 to 8 schizocytes per field (x10 objective), the causal pathology must be sought. They are found in cases of mechanical haemolysis, severe burns, thrombotic thrombocytopenic purpura, post-transplant (about 0.5 and $1 \%$ at follow-up), Biermer's anaemia, but also in premature newborns and in cases of haemolytic uremic syndrome [11, 12].

Elliptocytes are elliptical erythrocytes, which are objectified mainly in the case of hereditary elliptocytosis, melanesian ovalocytosis (ovalocyte striations), pyropoikilocytosis, thalassaemia (in the small percentage), and in cases of congenital dyserythropoiesis.

Dacryocytes, also called tear or pear red blood cells. These are elongated red blood cells characterized by one rounded end and the other (opposite) tapered but with a rounded tip. They result from the purifying action of the spleen which extracts inclusions. They are mainly found in thalassemia, primary or secondary myelofibrosis, bone marrow metastases and hemolytic anemia of the Heinz body. In thalassemia, pear red blood cells are related to the suppression of hemoglobin precipitates by the spleen.

Stomatocytes are red blood cells characterized by a rectilinear central depression giving a "buccal" appearance, hence the name buccal cell. This abnormality is usually present on blood smears of patients with hereditary stomatocytosis. It is also present on the smears of patients with no RH phenotype, and in Tangier disease (absence of high density lipoproteins) where stomatocytosis is associated with moderate hemolytic anemia $[13,14]$.

Acanthocytes, or spike cells, are red blood cells with multiple irregularly distributed cytoplasmic projections. Abnormal erythrocytes are observed in $\alpha$-lipoproteinemia, amyotrophic chorea, anorexia nervosa, severe hepatocellular insufficiency and hypothyroidism [15] Figure 3.

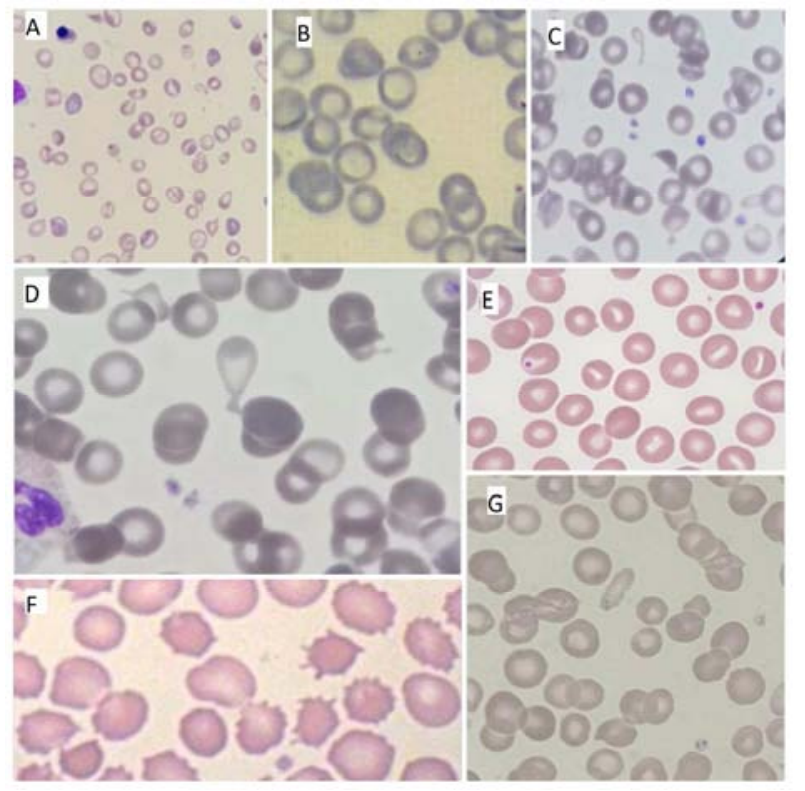

Figure 3. Blood smears showing, A: anisocytosis, microcytes, macrocytes, B: annulocytes, $C$ : Schizocytes, $D:$ dacryocytes, $E:$ stomatocytes, $F$ : acanthocytes, $G$ : elliptocytes (x100).

Red blood cells in targets (codocytes) are characterized by a colored center surrounded by a clear area delimited by a colored area (in the target). They have 3 concentric regions: a hemoglobinized central region, a clear intermediate region and a hemoglobinized periphery. Codocytes are caused by an increase in the surface-to-volume ratio of the erythrocyte. There is a relative excess of membrane which may be the consequence of a reduction in the amount of intracellular 
hemoglobin, which is observed in thalassemia and hemoglobin $\mathrm{E}$ or $\mathrm{C}$. This abnormality is not specific to hemoglobin pathology as it is found in iron deficiency anaemia, myelosclerosis, after splenectomy and in severe liver disease $[14,16]$.

Echinocytes have a uniformly crenellated surface (fine and regular projections). Although their discovery on a blood smear is often an artifact related to blood storage, contact with glass or high $\mathrm{pH}$, several hemolytic anaemias have been reported to be associated with echinocytosis of blood. Mild hemolytic anemia in long-distance runners and in patients with hypomagnesemia and hypophosphatemia (probably due to reduced intracellular ATP stores), uricemia due to an unknown plasma factor and pyruvate kinase (PK) deficiency. Sickle cell disease cells have a deformed and elongated structure, often sickle-shaped. This deformation is the consequence of polymerization of haemoglobin $\mathrm{S}$ in the form of long fibres in an oxygenated medium. They are found in homozygous sickle cell patients and in haemoglobin S / C, S / $\beta$ thalassemia $[13,14,16]$.

Spherocytes are characterized by an increased thickness (of the order of $3 \mu$ ) and a reduced diameter $(6 \mu)$, which has often wrongly called them "microspherocytes". They are easily recognizable on smears by their small size and especially by the absence of a clear central area. They are uniformly coloured and appear to be more charged with haemoglobin.

Spherocytes are not specific for hereditary spherocytosis (Minkowski-Chauffard disease). They are also found in pyropoïkilocytosis, absence of $\mathrm{Rh}$ antigen, autoimmune hemolytic anaemia (AIHA) and in toxic, mechanical and infectious haemolysis. In the neonatal period, it is sometimes difficult to differentiate hereditary spherocytosis from ABO incompatibility where the level of spherocytes may be so high.

In hereditary spherocytosis, when the abnormality affects the band 3 protein gene, some spherocytes take on the appearance of a fungus, sphere with foot $[14,17,18]$.
Phantom red blood cells are erythrocytes completely emptied of their hemoglobin content (phantom) or partially emptied with an irregular edge of the emptied portion (hemighost). This abnormality is observed in patients with Glucose-6-phosphate dehydrogenase (G6PD) deficiency in severe hemolytic crisis after the intake of oxidizing molecules. It is also observed in patients with hemolysis secondary to toxic methemoglobinizing agents $[13,14]$.

Intraerythrocytic inclusions: these are rounded or irregular granulations formed from aggregates of ribosomal RNA and polyribosomes. They are found in thalassemia, unstable haemoglobin, constitutional pyrimidine 5 'deficiency and acquired nucleotidase deficiency, and in any chronic regenerative anaemia $[14,19]$ (Table 4) Figure 4.

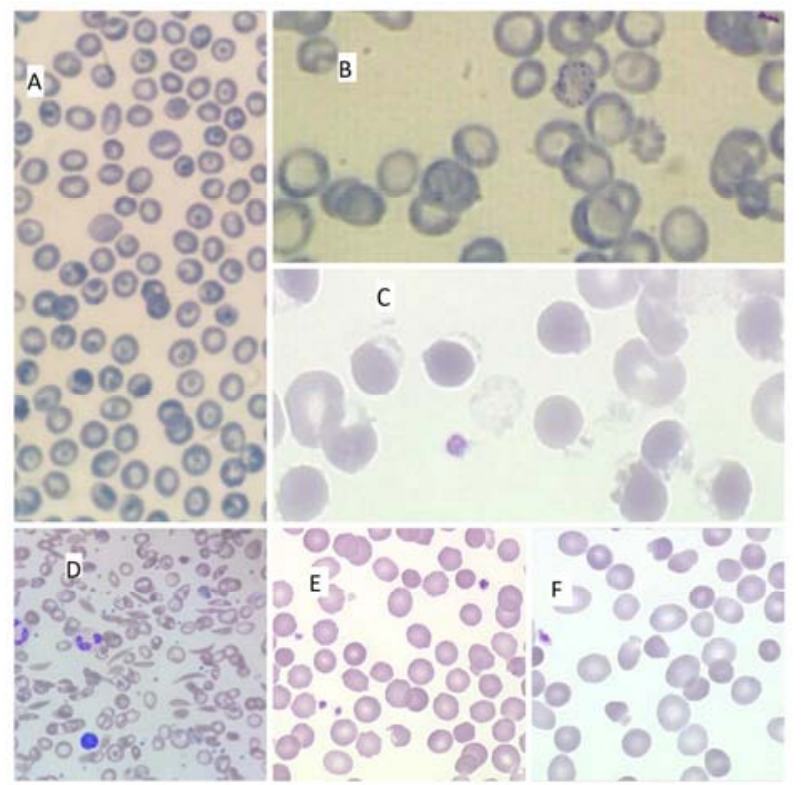

Figure 4. Blood smears showing, A: sickle cell, B: basophilic punctuations, $C$ : phantom red cells, D: sickle cell, E: spherocytes, F: Mushroom-shaped Red Blood Cells (x100).

Table 4. Intraerythrocytic inclusions and the pathologies with which they are associated [19, 20].

\begin{tabular}{lll}
\hline Anomaly & Description & Frequent situations \\
\hline Howell-Jolly's body & Spherical body $(0.5-1 \mu \mathrm{m})$ & Post-splenectomy \\
& MGG purple stained (core chromatin remnant) & Functional asplenia \\
Pappenheimer's body & Small iron-containing granules $(0.2-0.5 \mu \mathrm{m})$ & Sideroblastic anemias \\
& Thalassemias after splenectomy & Functional asplenia \\
Basophile punctuations & Present at the cytoplasm & 5'nucleotidase deficiency \\
& Stained blue with MGG (ribosome and DNA & Thalassemias \\
& aggregates) & Chronic regenerative anaemias \\
& Evidenced by the blue coloration of cresyl & G6PD deficiency \\
Heinz body & Thalassemias \\
& red blood cells. & Unstable hemoglobins \\
& & Glutathione metabolism enzyme deficiency \\
\end{tabular}

Interpretation of these red blood cell anomalies can be tricky, as the same morphological anomaly can be found in several deficits. Similarly, several constitutional deficits may be combined in the same individual. Thus, a membrane abnormality may be associated with hemoglobinopathy and/or enzyme deficiency. These associated pathologies may be accompanied by unusual images that are difficult to interpret. For example, the hereditary spherocytosis smear associated with thalassemia includes spherocytes and target red blood cells. Thus, it should be remembered that anemia 
with the presence of several red blood cell targets should lead to a search for haemoglobin pathology with haemoglobin electrophoresis and a martial assessment [21]. The presence of numerous elliptocytes suggests elliptocytosis and if there is also significant fragmentation of red blood cells, it is advisable to study the deformation of the red blood cells and electrophoresis of the membrane proteins in order to determine the membrane anomaly in question [22].

In hereditary enzyme deficiencies, the morphological abnormalities are more discrete, except for the "hemighost" observed in G6PD deficiency, in hemolytic seizures caused by severe oxidative stress. In subjects with PK deficiency, the blood smear shows no specific morphological abnormalities [14, 23].

\section{Conclusion}

The blood smear plays an essential role in the diagnosis of anemia in children because it confirms the data provided by the automaton and recognizes morphological abnormalities that the automaton has not emitted or is unable to detect. Thus, the study of the morphology of the erythrocytes makes it possible to guide the diagnosis, particularly of constitutional pathologies of the red blood cell. Indeed, abnormalities of the red blood cell membrane, haemoglobin and enzyme content are responsible for morphological changes in red blood cells. Thus, the association between the clinical history and the haemogram data, supplemented by a careful reading of the blood smear, makes it possible to propose a diagnosis, the confirmation of which will be provided later by more sophisticated examinations $[2,4,9]$.

\section{Declaration of Interest Links}

All the authors do not have any possible conflicts of interest.

\section{References}

[1] Organisation mondiale de la santé. Focaliser sur l'anémie: vers une approche intégrée pour un contrôle efficace de l'anémie. 2005.

[2] Martinaud C, Gaillard T, Gisserot O, De Jauréguiberry JP, Graffin B, Brisou P, et al. L'intérêt de l'examen attentif du frottis sanguin dans le diagnostic des anémies hémolytiques. Ann Biol Clin 2007; 65 (3): 271-6.

[3] Robertson J, Shilkofski N. Le manuel Harriet Lane. $17^{\text {ème }}$ éd. Philadelphie, Pennsylvanie: Mosby; 2005: 337.

[4] Lainey E, Boirie M, Fenneteau O. Hémogramme en pédiatrie: variations physiologiques. Revue Francophone Des Laboratoires Novembre 2009; 416: 49-59.

[5] Binet $C$, Zandecki $M$, et al. Hématologie: orientation diagnostic devant une anémie. Paris: Elesevier Masson: 2011.

[6] Haferlach T, Bcher U, Theml H, Diem H. Atlas de poche Hématologie: anomalies des hématies et des plaquettes. $3^{\text {éme }}$ édition. Paris: Lavoisier: 2014.
[7] Cloutier L, René A, Jutras A. La formule sanguine complète. Pratique clinique. Janvier-février 2014; 11 (1): 28-32.

[8] Zandecki M, Ugo V. Morphologie érythrocytaire, principes généraux d'observation, anomalies divers. 2012. Disponible sur: www.hematocell.fr.

[9] Geneviève F, Galoisy A C, Mercier-Bataille D, Wagner-Ballon $\mathrm{O}$, Trimoreau F, Fenneteau O, et al. Revue microscopique du frottis sanguin: propositions du Groupe Francophone d'Hématologie Cellulaire (GFHC). Feuillets de Biologie Mars 2014; 317: 7-16.

[10] Émile C. Démarche diagnostique devant une anémie. OptionBio avril 2009; 20 (416): 19-21.

[11] Lainey E, Fenneteau O. Particularités de la numération formule sanguine et apport de la cytologie en période néonatale. Revue Francophone Des Laboratoires Mars 2018; 500: 36-47.

[12] Lesesve J-F, Fenneteau O, Coppo P, Zini G. Schizocytes: détection, reconnaissance morphologique et automatisée, mesure, interprétation. Biologie Médicale Juin 2013; 8 (2): 1-11.

[13] Zandecki M, Ugo V. Morphologie érythrocytaire: anomalies de forme des GR. Septembre 2012. Disponible sur: www.hematocell.fr.

[14] Fenneteau O. Anomalies morphologiques érythrocytaires. Horizons Hémato Janvier- Février-Mars 2014; 04 (01): 31-34.

[15] Perrin J, Georges A, Morali A, Vigneron C, Lecompte T, Lesesve J-F. Acanthocytes et hypocholestérolémie. Annales de Biologie Clinique Septembre-Octobre 2008; 66 (5): 569-72.

[16] Fenneteau O. Cytologie hématologique en pédiatrique. OptionBio Jeudi 17 décembre 2009; 428: 14-15.

[17] Becheur M, Bouslama B, Slama H, Toumi N E H. Anémie hémolytique auto-immune de l'enfant. Transfusion Clinique et Biologique 2015. 22: 291-298.

[18] Guittonl C. Sphérocytose héréditaire. Horizons Hémato Janvier-Février-Mars 2014; 04; (01): 19-20.

[19] Solis M, Perrin J, Guédenet J-C, Lesesve J-F. Inclusions érythrocytaires après splénectomie: pas seulement des corps de Howell-Jolly !. Ann Biol Clin 2013; 71 (2): 185-9.

[20] Zandecki M, Ugo V. Morphologie érythrocytaire: anomalies de couleur, de contenu, inclusions. Septembre 2012. Disponible sur: www.hematocell.fr.

[21] Ben Hamoudaa H, Mahjouba B, Souaa H, Laradib S, Miledb A, Sfar M T. Expression néonatale d'un trait bêta thalassémique associé à une sphérocytose héréditaire chez deux jumelles monozygotes. Archives de Pédiatrie 2016; xxx: $1-5$.

[22] Debray F G, Ilunga S, Brichard B, Chantrain C, Scheiff J M, Vermylen C. Une forme particulière d'anémie constitutionnelle chez un nourrisson de deux mois: l'elliptocytose. Archives de pédiatrie 2005; 12: 163-167.

[23] Zandecki M, Ugo V. Déficit en G6PD, en pyruvate kinase, en pyrimidine 5 ' nucléotidase. Février 2009. Disponible sur: www.hematocell.fr. 